\title{
MOTIVATING PROFESSOR AND STUDENTS THROUGH SIGNIFICANT LEARNING IN STATISTICS CLASSES
}

\author{
Mauren Porciúncula and Suzi S. Pinto \\ Federal University of Rio Grande - FURG, Brazil \\ mauren@furg.br
}

This paper presents an analysis of the speeches of the students about the educational proposal for the Statistics course conducted based on the Significative Learning Theory, characterized by Moreira (2012). The importance of this analysis is justified by the findings of Joan Garfield and Dani Ben-Zvi (2008), when considered that the difficulties of Statistical learning lies in the fact that the teaching method is focused on exercises prepared by the professor. The design of this Statistic Course had a starting point situation problems made by the students, with themes of their interests. To analyze the results of this process, the qualitative methodology of the Collective Subject Speech was used. Outcome we obtained speeches of students who actually said that they have learned Statistics. These findings allow us to conclude that this experience promoted the motivation of students and also the professor.

\section{INTRODUCTION}

The pedagogical practice traditionally used by many professors in statistical classes, and recognized by society, is that in which the professor teaches only through orality. In this practice, the student passively listen, then mechanically reproduce in the tests.

As a result of this form of teaching and learning, we have observed students unmotivated and with difficulties in learning statistics. Garfield and Ben-Zvi (2008) find that students' difficulties, with respect to learning, lie in the fact that, in most cases, the teaching method is focused on problems previously prepared and selected by the professor. Thus, it is up to the student only solve them by simply applying statistical techniques.

Viali (2007) supports the need for new approaches for the teaching of Statistics. To the author's the focus on solving calculations, applying formulas or exercises, which do not come close the student reality, causes this little interest for the subject to be rapidly lost.

For the transformation of the traditional pedagogical practice, we attempted to build a reasoned educational environment based on the Significative Learning Theory in the perspective presented by Moreira (2014). The author advocates the abandonment of the orality of the professor as a classical model, as this leads to rote learning of short duration which serves only to pass examinations. The author argues toward a focused education in active student participation, with collaborative activities that encourage the negotiation of meanings, the criticality, facing the learning how to learn. Accordingly, this paper aims to analyze the speeches of the students on the educational proposal for the statistics course conducted based on the Significative Learning Theory.

\section{TEACHING EXPERIENCE}

This paper presents a research conducted during the year 2014 in a Statistics Course taught to psychology students. The paper aims to analyze the impressions of these students who participated in an educational experience planned through the Significant Learning.

To minimize the problems described in the previous section, this statistic Course had as its starting point the development of problem situations by the students themselves, with themes of their interest. According to Moreira (2011) these problem situations may involve the content to be processed but not to start to teach it; "Such problem situations can work as prior organizer; these are situations that give meaning to new knowledge, but to do so, students must perceive these situations as problems and should be able to model them mentally "(p. 45). The problem situations were analyzed and resolved throughout the Course, in an interactive and cooperative way. In this context, the professor does not assume the role of lecturer of the classes, but teaching organizer, potentially significant situations provider and mediator of the capturing of meanings (Moreira, 2011). The teaching organizer would provide materials on the content and make little explanations,

In: M.A. Sorto (Ed.), Advances in statistics education: developments, experiences and assessments. Proceedings of the Satellite conference of the International Association for Statistical Education (IASE), July 2015, Rio de Janeiro, Brazil. 
according to the previous knowledge of the students, their needs, and the curriculum requirements of the course.

At the beginning of the course the professor introduced all the content to be taught to the students, by delivering summaries of content and examples. From this material it was requested that students, in groups, to create problem situations in Psychology, one for each topic content. This proposal aimed to promote the establishment of relationships among topics to be studied and the interest of students. This creation activity of problem situations was carried out in groups, in order to provide interaction for exchanging experience and cooperation to create the activity. Assuming the interaction as a precondition for learning, requires, according to Pellanda (2009), to rethink the practices and teaching strategies. This rethink should be done to enable the effective participation of each student on building their knowledge.

Once the professor has the situations developed by groups, it was planned all other meetings. For each of the meetings it was created a material, organized as follows: content (extracted from references); resolved problem situation (taken from references); situation-problem to solve (written by students). These problem situations, created by the students, passed by a careful analysis of the professor in order to see if there was environment in the topic indicated by the students, and if it considered all data necessary for their resolution, and if it was not against ethical and linguistic issues .

In each class, the professor would give the students the specific material topic to be studied that day, and make a brief explanation of the content. As a group, the students would read and resolve, collectively, the problem situation created by themselves or by other group. After the resolution of the problem situation, students delivered individually a resolved problem situation, as well as a description of the conclusion obtained, and they also recorded what was learned that day and what were their doubts. All this material was being evaluated by the professor, allowing a procedural and continuous evaluation until the end of the course.

At the completion of all planned activities, it was asked the students to write an essay to contemplate the following aspects: what I learned; I have questions / insecurities; self-assessment; evaluation methodology of the entire course. With all of the individual activities of each meeting, and the final writing, the professor reviewed and issued a descriptive opinion for each student, and recorded in the final assessment.

\section{RESEARCH METHODOLOGY}

The appreciation of the final writing of the students about the evaluation of the methodology of this course is the subject of this research. To this end, a qualitative approach was used, through discourse analysis of the collective subject (DCS), which involves the construction of speeches by uniting the individual manifestations of student's fragments. These fragments constitute the most important parts of the manifestations of each student, denominated of key expressions. By the end, it was possible to identify the main idea of each key expression, which, according to Lefèvre and Lefèvre (2005a and 2005b), is a name or a linguistic expression, that names in a synthetic way, the direction of each one of the analyzed speeches. With the main ideas and key expressions with a similar meaning or equivalent, it was made up one or more short speeches, written in the first person of singular.

\section{RESULTS AND DISCUSSION}

By questioning about the pedagogical practice, the teachers realize that their methods cannot always accomplish the task of teaching and learning. The perception that knowledge is provisional leads professors to improvise, to explore other teaching methods and work resources, building actions and trusting in situations other than those previously experienced.

This perception has led the search for the transformation of traditional pedagogical practice in the Statistics Course towards building an educational environment based on the Significative Learning Theory. In Table 1, we present the collective discourse built from the perception of the Psychology course students about the experience lived in the Statistics course.

Table 1 - The redefinition of the space of teaching and learning statistics 
Before I have done Statistics II, I've never imagined that one day I would find the real meaning of studying statistics. Here in this course, I learned that statistics can be in everything. It is useful, it makes life easier for researchers and professionals who have to deal with data. I believe that the commitment of the teacher contributed to it, because every doubt of mine, I resorted to the professor, and the professor answered me with total dedication. The methodology is clear and objective and also the material is very good. The way the course was organized favored learning, which was more significant, since our participation in the construction of knowledge was much more effective. I could feel an integral part of the teaching and learning process. I loved the part we thought of examples of each method. I believe that the way of thinking at "reverse" helped to better understand the results and the need for applying the methods. I found it very peaceful to learn and more exciting, too. Group work is always positive. I enjoyed a lot the fact that we used examples of psychology studies to understand each application. Doing the activities in class was very productive, because with the monitoring of the professor it was possible to learn from our mistakes immediately. Making problem _ in class and understanding why we are conducting the activity, was really pleasant and made possible to exercise the interpretation and to perform the calculations. The division of the contents and the continued evaluation that was performed in the course gives a dynamism to the class and holds the attention of the student.

Source: own elaboration

From the DCS it can be seen that the development of problem situations by the students themselves, with themes of interest, made the learning process of the most significant statistical concepts for them, increasing their interest and willingness to learn. These are two essential conditions to achieve significant learning (MOREIRA, 2012). Also according to the author, the attribution of meaning to new knowledge on the existence of specifically relevant prior knowledge for the student and the interaction between them. To Ausubel (1968) prior knowledge is the most important variable for significant learning of new knowledge.

Another important factor to be highlighted in the DCS concerns the recognition, by the students, the importance of teamwork for interaction, as shown in the following excerpt: "Group work is always positive". According to Moreira (2012) collaborative activities have great potential to facilitate significant learning because enable the negotiation of meanings, exchange, and put the professor in the role of mediator. Garfield (2013) cooperative work improves communication skills, the ability to work in teams, and enables students to restructure the new statistical concepts adding them in their own cognitive structures.

The strategy adopted in this course enabled the student took advantage of the error as learning factor, as can be seen in the following excerpt of the DCS: "Doing the activities in class was very productive, because with the monitoring of the professor it was possible to learn from our mistakes immediately". According to Moreira (2005) "the humans learn correcting their mistakes. There is nothing wrong with making mistakes. What is wrong is to think that certainty exists, that truth is absolute, that knowledge is permanent "(p. 94).

In the DCS the students also highlight the importance of the evaluation process of the course and its influence on their motivation to take part of the classroom activities, as can be seen in the following excerpt: "The division of the contents and the continued evaluation that was performed in the course gives a dynamism to the class and holds the attention of the student". The significant learning is progressive, so the importance of assessing the progress of each student is made at each stage of their learning. This process evaluation is a continuous evaluation and it is concerned with the presented meanings and catchment by the student process (Moreira, 2011).

The students, under the supervision of the professor, analyze if the activities were done or not and they do the self-assessment. In the few cases of failure, it is observed that the students are still rooted to the traditional method of teaching, and possibly they have not adapted to a learning process that requires further action of their part. 


\section{CONCLUSION}

As a result of this form of teaching and learning can be observed the students motivation with the possibility of continuously present questions, and take the help of the professor and colleagues to minimize their difficulties in learning statistics. This motivation is attributed to:

- Authorship of students, when preparing thematic with problem situations they have chosen, providing the awakening of interest;

- Teamwork, which allows students, through interaction, the incorporation of new statistical concepts to their cognitive structures;

- Error by learning, when they come to see the error with something positive, taking advantage of it as learning factor;

- Continuous evaluation, not as a point, which minimizes the fear of having to demonstrate their knowledge in a single moment - in the test, but procedural, progressive, performed by analysis of development / progress of each student.

These aspects become the learning process pleasurable. The error is not punished. It is learned about what you like and with whom you want. And the evaluation is a picture of learning of statistical concepts and their significance for students.

We believe that, for the incorporation of the Theory of Significant Learning in Statistics classes, in addition to knowledge of their theoretical presupposes and the planning of actions from these presupposes, depends on an approach of the professor. It is up to the professor to recreate himself/herself and continually seek a balance between the content provided in the Course and the individuality of students.

It is expected that this teaching experience, here reported and analyzed, can provide support for motivation of professors and students, and for the benefit of teaching and learning statistics.

\section{REFERENCES}

Ausubel, D. P. (1968). Educational psychology: A cognitive view. New York: Holt, Rinehart \& Winston.

Garfield, J. (2013). Cooperative Learning Revisited: From an Instructional Method to a Way of Life. Journal of Statistics Education. 21(2), 1-9.

Garfield, J., \& Ben-Zvi, D. (2008). Developing Students' Statistical Reasoning Research and Teaching Practice. Springer Publishers.

Moreira, M. A. (2005). Aprendizaje Significativo Crítico. Indivisa: Boletín de Estudios e Investigación, 6, 83-102.

Moreira, M. A. (2011). Unidades de Enseñanza Potencialmente Significativas - UEPS. Aprendizagem Significativa em Revista. 1(2), 43 - 63.

Moreira, M. A. (2012). O que é afinal aprendizagem significativa? Qurriculum, La Laguna, Espanha, 25, 29-56.

Moreira, M. A. (2014). Abandono da narrativa, ensino centrado no aluno e aprender a aprender criticamente. Disponível em: http://www.if.ufrgs.br/ moreira/Abandonoport.pdf

Lefèvre, F., \& Lefèvre, A. M. C. (2005a). Discurso do Sujeito Coletivo: um novo enfoque em pesquisa qualitativa. (2a ed). Caxias do Sul: Educs.

Lefèvre, F., \& Lefèvre, A. M. (2005b). Discurso do Sujeito Coletivo. Disponível em: http://www.fsp.usp.br/ flefevre/Discurso_sujeito_coletivo.htm.

Pellanda, N. M. C. (2009). Maturana \& a Educação. Belo Horizonte: Autêntica.

Viali, L. (2007). Aprender fazendo: como tirar proveito do computador para melhorar a aprendizagem da estatística. Anais do IX ENEM, Belo Horizonte. 